LS-283

Addendum 1

\title{
Radiation Dose Measurements of the Insertion Devices
}

\author{
J. Alderman, E. Semones, and P.K. Job \\ APS Operations Division \\ Advanced Photon Source
}

February 26, 2001

Results of radiation dose measurements of the insertion devices for the year 2000 have been added as Figures 29-35. 


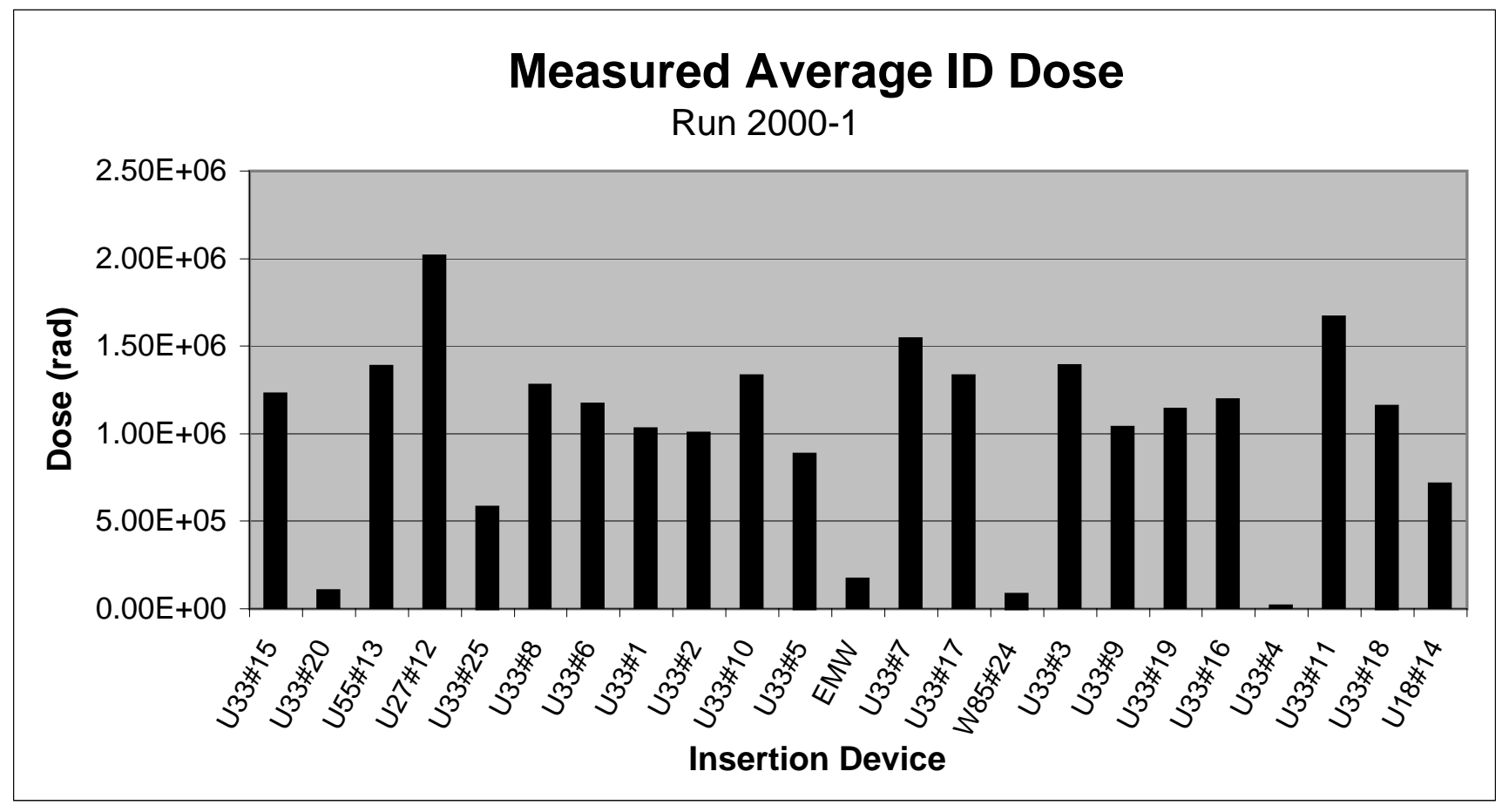

Figure 29: Measured Average Insertion Device Doses for Run 2000-1

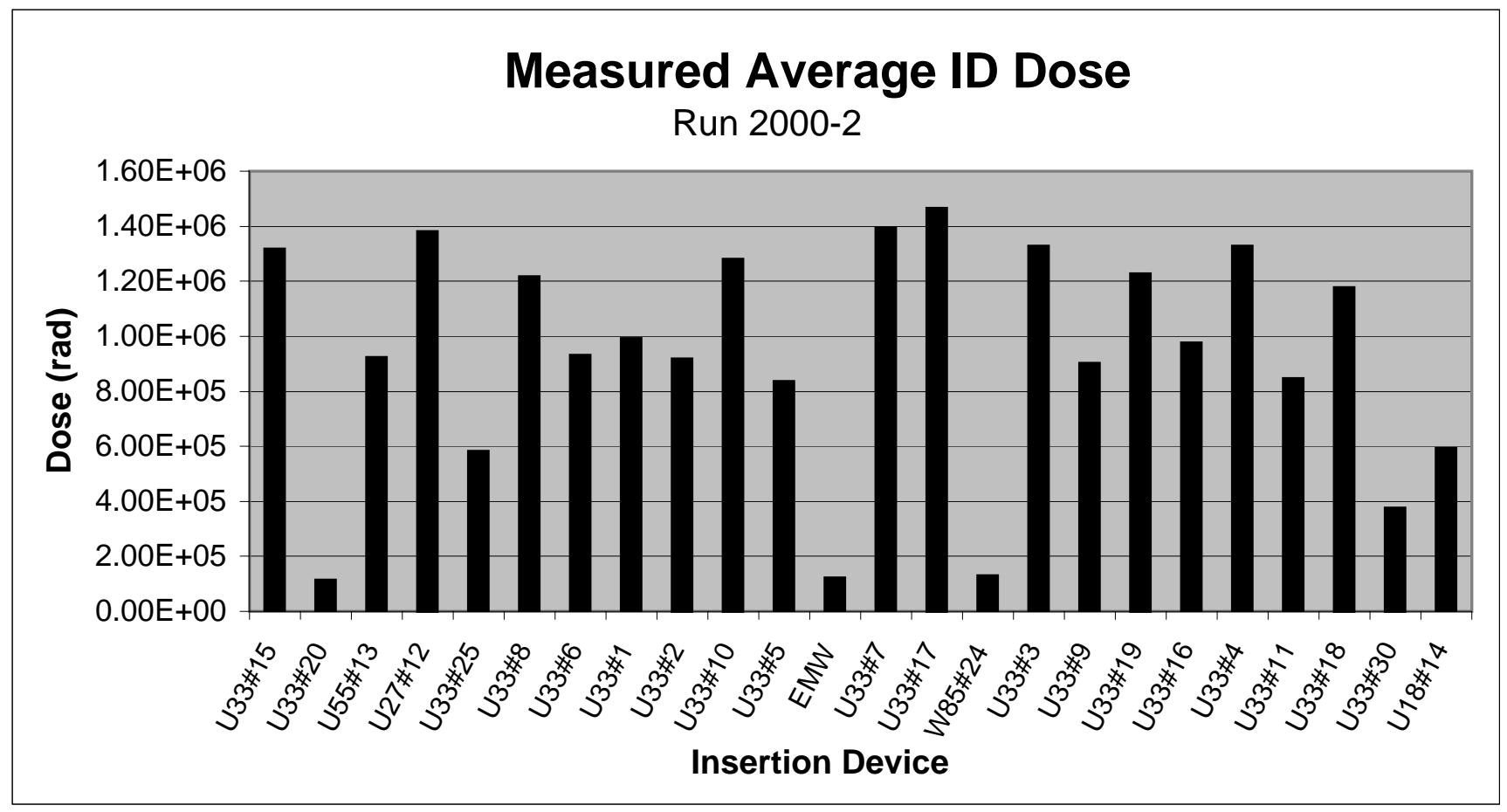

Figure 30: Measured Average Insertion Device Doses for Run 2000-2 


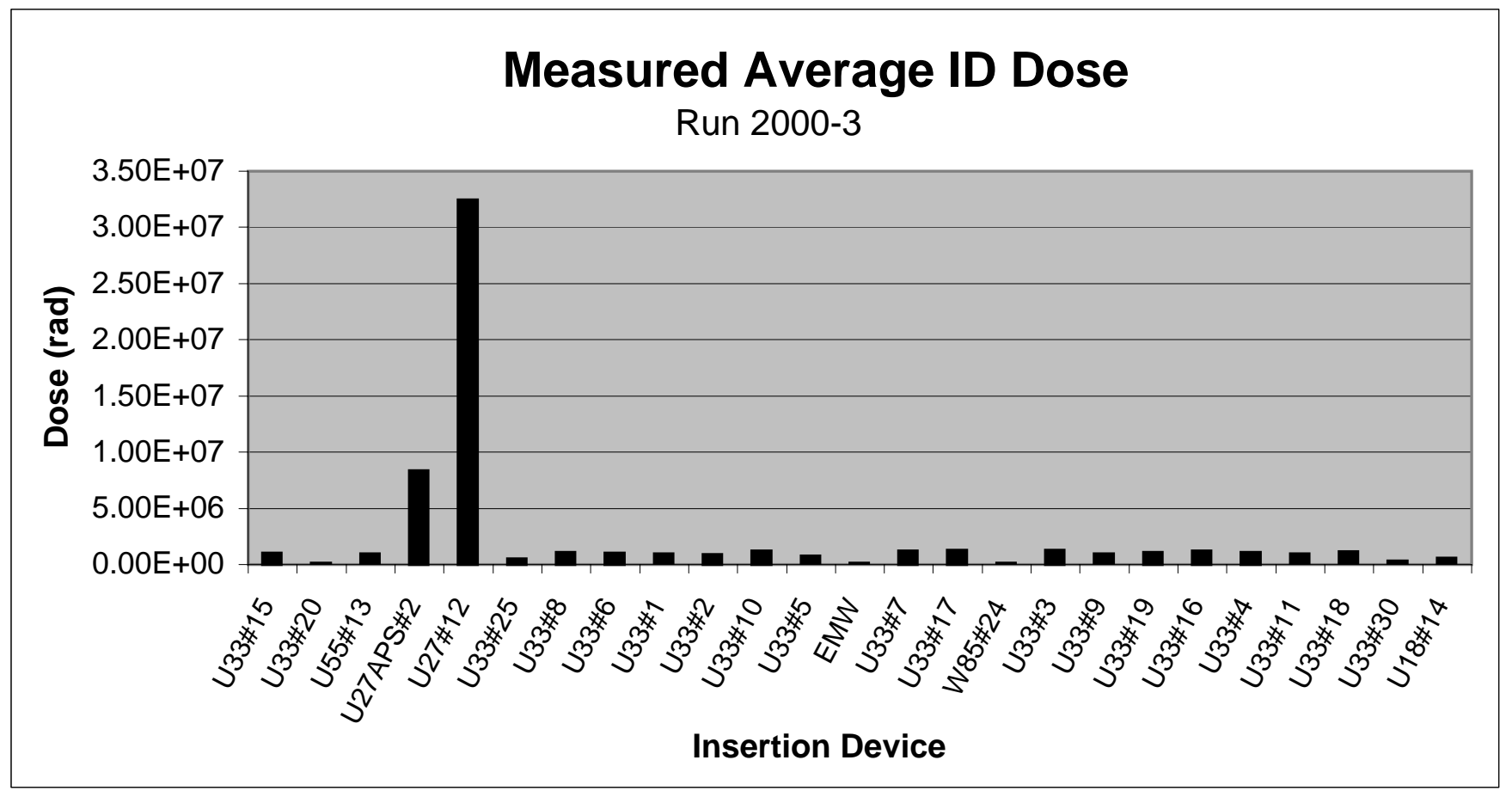

Figure 31: Measured Average Insertion Device Doses for Run 2000-3

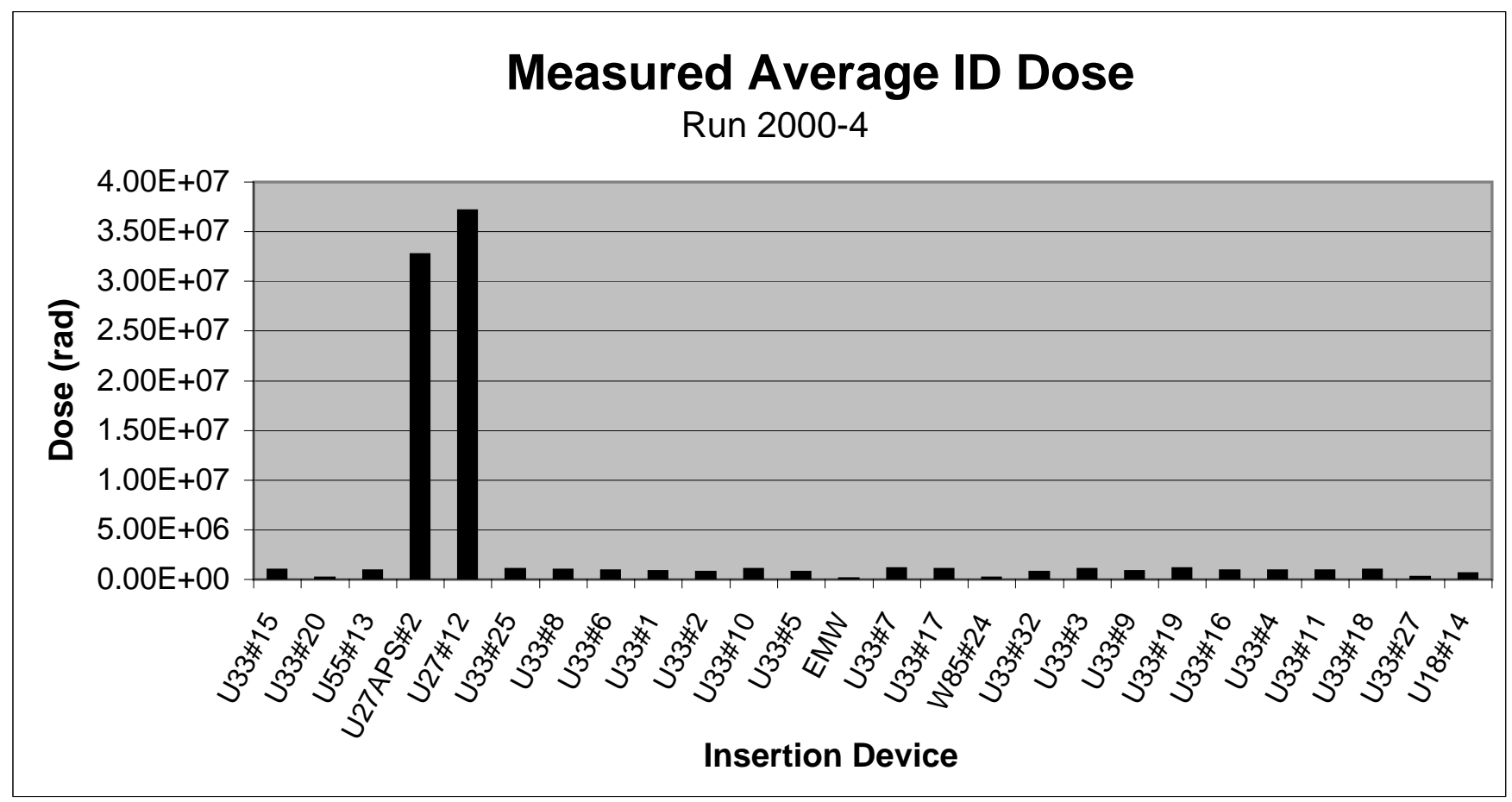

Figure 32: Measured Average Insertion Device Doses for Run 2000-4 


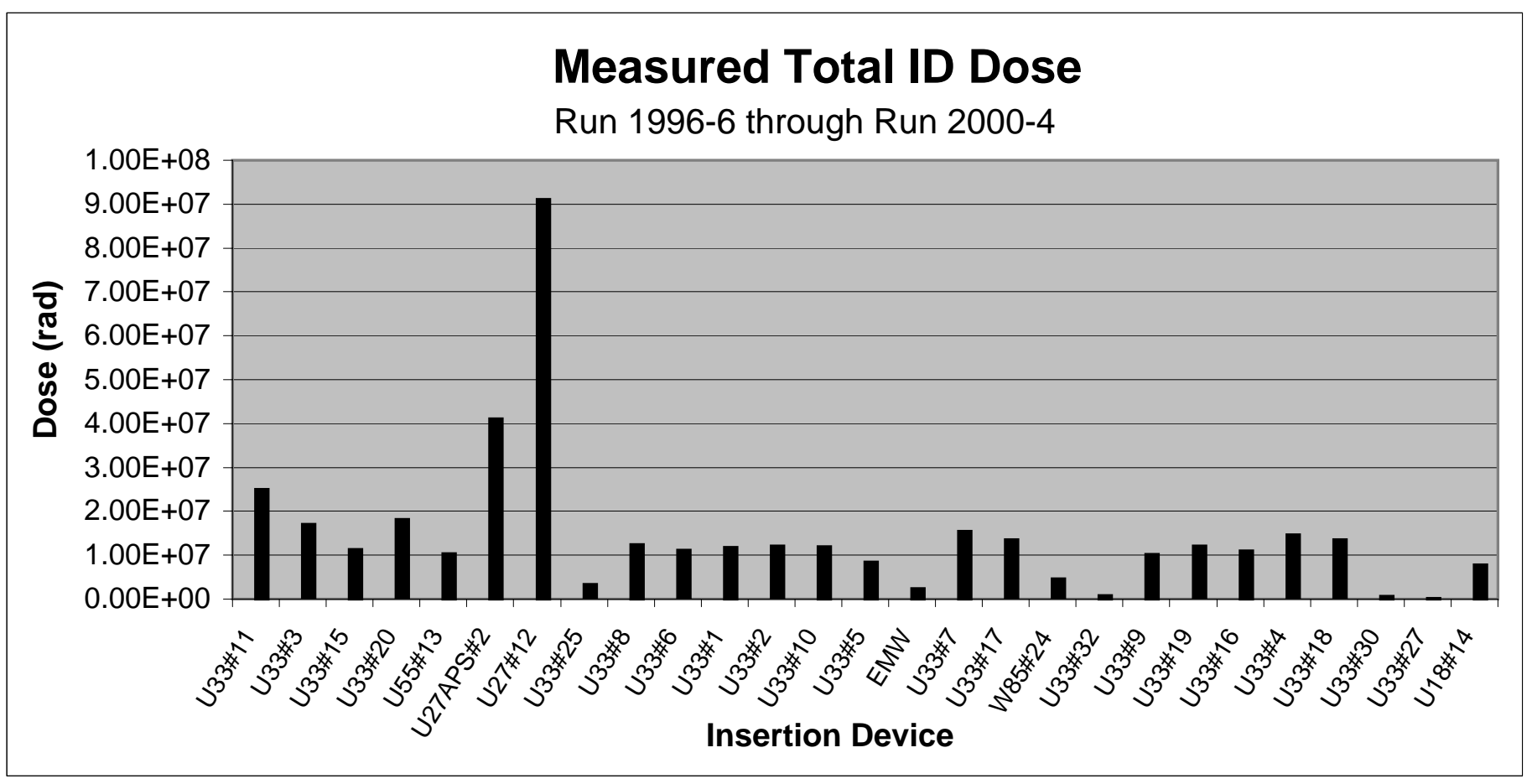

Figure 33: Measured Total Insertion Device Doses for Run 1996-6 to Run 2000-4

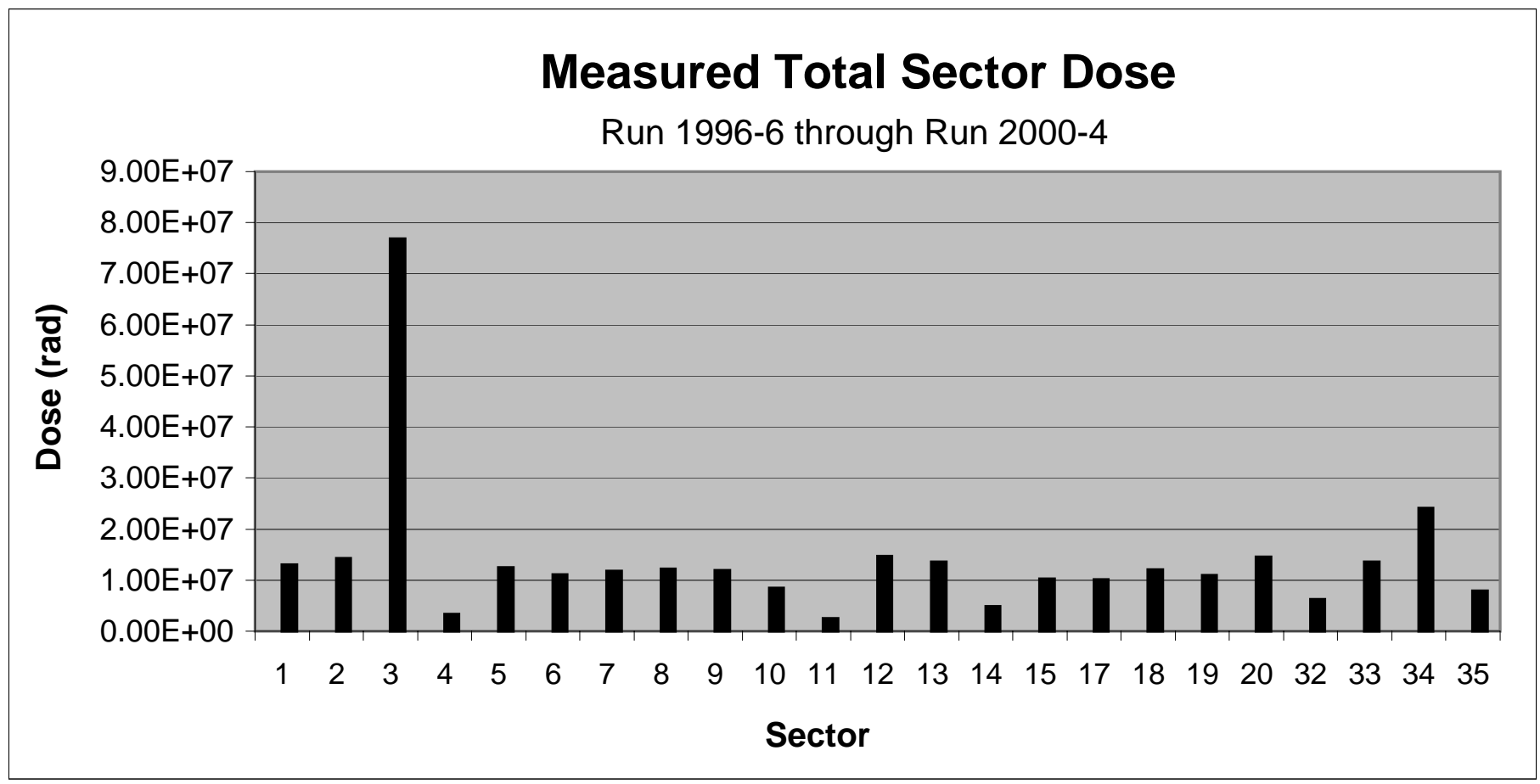

Figure 34: Measured Total Sector Doses from 1996-6 to 2000-4 


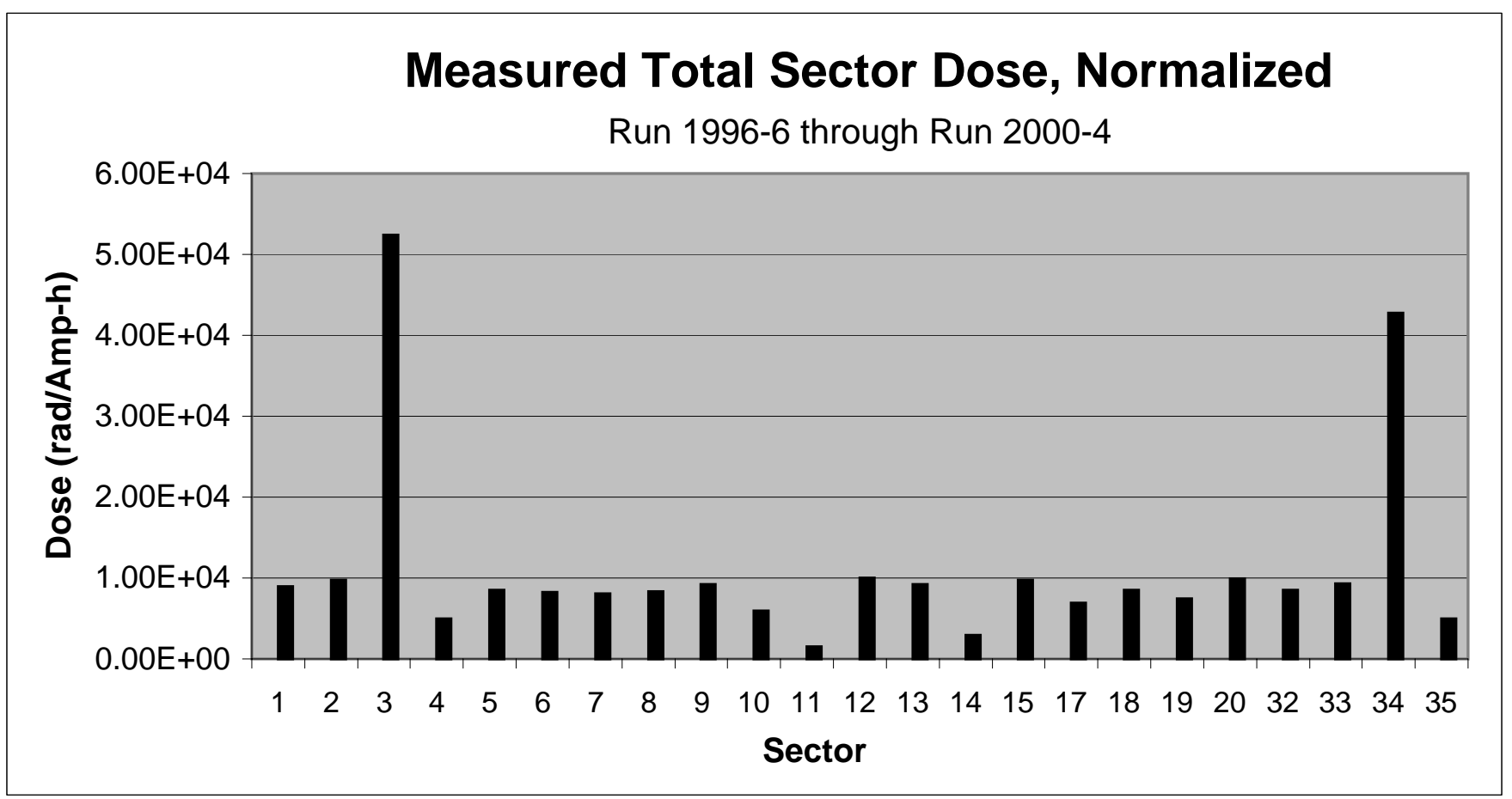

Figure 35: Normalized Sector Doses from 1996-6 to 2000-4

Go to LS-283 Addendum 2 - 2001 